\title{
A Study of High-energy Milling for the Production of Sintered PrFeB Magnets
}

\author{
Elio Alberto Périgo ${ }^{\text {a*, Edson Pereira Soares }}{ }^{\text {a }}$, Ricardo Mendes Leal Neto ${ }^{\text {, }}$ \\ Cláudio Costa Motta ${ }^{\text {b }}$ Rubens Nunes de Faria Jr. ${ }^{\text {a }}$ \\ anstituto de Pesquisas Energéticas e Nucleares - IPEN/CNEN, \\ Av. Prof. Lineu Prestes, 2242, Cidade Universitária, 05508-000 São Paulo - SP, Brazil \\ ${ }^{\mathrm{b}}$ Centro Tecnológico da Marinha em São Paulo - CTMSP, \\ Av. Prof. Lineu Prestes, 2468, Cidade Universitária, 05508-900 São Paulo - SP, Brazil
}

Received: March 21, 2007; Revised: August 28, 2007

\begin{abstract}
Sintered $\operatorname{Pr}_{16} \mathrm{Fe}_{76} \mathrm{~B}_{8}$ magnets have been produced using the hydrogen decrepitation (HD) process and highenergy planetary ball milling. Investigations have been carried out to evaluate the influence of the milling speed and time. The best magnetic properties obtained were $\mathrm{B}_{\mathrm{r}}=(1020 \pm 20) \mathrm{mT}, \mu_{0 \mathrm{i}} \mathrm{H}_{\mathrm{c}}=(1420 \pm 30) \mathrm{mT}$ and $(\mathrm{BH})_{\max }=$ (200 \pm 4$) \mathrm{kJm}^{-3}$, for a magnet prepared with the alloy milled at $200 \mathrm{rpm}$ for $4.5 \mathrm{ks}$. Magnets prepared from this powder exhibited a superior intrinsic coercivity compared to that of magnets produced using low-energy ball milling. However, the remanence and energy product of the latter were somewhat lower. An important feature was the dramatic reduction in the processing time (about 90\%). Microstructural observation have shown that increasing the milling time and keeping constant the rotational mill speed caused an exponential grain size reduction in the sintered magnet. Increasing the milling speed also reduced the grain size and influenced both remanence and intrinsic coercivity.
\end{abstract}

Keywords: high-energy milling, hydrogen decrepitation, $\operatorname{PrFeB}$

\section{Introduction}

The production of REFeB $(\mathrm{RE}=\mathrm{Pr}, \mathrm{Nd})$ sintered magnets involves a multistep process ${ }^{1}$. It is possible to identify at least seven steps: melting of the alloy, homogenization, milling, powder magnetic alignment and compaction, sintering and post-sintering heat treatment. Good HD sintered REFeB magnets have been produced using the "roller" ball milling (RBM) from alloys comminuted between 64.8 and $72.0 \mathrm{ks}$ (18 and 20 hours, respectively $)^{2,3}$. However, milling is time consuming, even using the hydrogen decrepitation (HD) process. If production costs are considered, reducing the processing time is essential, without changing significantly the magnetic properties.

Few works report about high-energy milling technique to prepare sintered magnets ${ }^{4-7}$. However, none of them reports the use of planetary ball milling.

This paper addresses this aspect and reports work carried out to produce $\mathrm{PrFeB}$ sintered magnets from HD powders milled for a short time using high-energy milling.

\section{Experimental}

A commercial $\operatorname{Pr}_{16} \mathrm{Fe}_{76} \mathrm{~B}_{8}$ (wt. (\%): 34.24Pr-64.45Fe-1.31B) alloy in the as-cast state was used in this study. To produce the sintered Pr-based magnets using the HD process, $(14.000 \pm 0.002) \mathrm{g}$ of the bulk ingot was placed in a stainless steel hydrogenation vessel which was evacuated to backing-pump pressure. Hydrogen was then introduced to a pressure of 2 bar which resulted in decrepitation of the bulk material. The decrepitated hydride material was transferred to a planetary ball mill Fritsch Pulverisette 5 and milled at several rotational speeds and for several times using cyclohexane as the milling medium. A preliminary evaluation showed that hydrogen is not an effective milling atmosphere due to the formation of agglomerates. Rotational speeds from 150 to $300 \mathrm{rpm}$ with steps of $50 \mathrm{rpm}$ and milling times from 1.8 to $5.4 \mathrm{ks}$ with steps of $0.9 \mathrm{ks}$ were used. Milling times longer than 5.4 ks were not practical due to difficulty to handle the extremely fine pyrophoric powder. On the other hand, it was verified that speeds below $150 \mathrm{rpm}$ yield a coarse powder, useless to produce good sintered REFeB magnets. No contamination has been found in any sample from the milling spheres or jar. Based on the magnetic properties obtained from the hydrogen decrepitated $\operatorname{Pr}_{16} \mathrm{Fe}_{76} \mathrm{~B}_{8}$ alloy milled for 1.8 and $2.7 \mathrm{ks}$, samples produced with longer times were investigated only for the speed of $200 \mathrm{rpm}$. Ballto-powder weight ratio was kept constant for all experiments (10:1). The resultant pyrophoric powder was dried for $1.5 \mathrm{ks}$ and transferred to a small cylindrical rubber tube under a nitrogen atmosphere. The resultant fine powder was then pulsed at a magnetic field of 6T, isostatically pressed at $200 \mathrm{MPa}$, vacuum sintered at $1333 \mathrm{~K}$ for $3.6 \mathrm{ks}$ (60 minutes) and furnace cooled.

Magnetic characterization of the HD sintered $\operatorname{Pr}_{16} \mathrm{Fe}_{76} \mathrm{~B}_{8}$ permanent magnets was carried out using a permeameter. Remanence $\left(\mathrm{B}_{\mathrm{r}}\right)$, intrinsic coercivity $\left(\mu_{0 \mathrm{i}} \mathrm{H}_{\mathrm{c}}\right)$ and maximum energy product $\left((\mathrm{BH})_{\max }\right)$ have been obtained from the second quadrant hysteresis curve. Microstructural observations were carried out using a scanning electron microscope. Grain size measurements were carried out using image analysis. Samples for grain analysis were etched with a solution of $25 \% \mathrm{H}_{2} \mathrm{O}-50 \% \mathrm{HCl}-25 \% \mathrm{HNO}_{3}(\%$ vol.) in order to reveal the grain boundaries.

\section{Results and Discussion}

The magnetic properties for the magnets produced from the alloy hydrogen decrepitated and milled for $1.8 \mathrm{ks}$ (30 minutes) are shown in Figure 1. Remanence reached a peak of $860 \mathrm{mT}$ for a milling speed of $200 \mathrm{rpm}$. This initial improvement in $\mathrm{B}_{\mathrm{r}}$ with the milling speed has been attributed to better alignment degree of the $\operatorname{Pr}_{2} \mathrm{Fe}_{14} \mathrm{~B}$ $(\phi)$ grains due to the reduction of the mean particle size. Rotational milling speed superior to $200 \mathrm{rpm}$ diminished the remanence with a minimum at $250 \mathrm{rpm}$, possibly due to formation of agglomerates of 
the fine powder. A number of variables affect the magnet production and the variation on the magnetic properties at $250 \mathrm{rpm}$ has been attributed to a processing drawback of this particular magnet. The magnet produced using a milling speed of $300 \mathrm{rpm}$ showed the best $\mu_{0 \mathrm{i}} \mathrm{H}_{\mathrm{c}}$. This has been attributed to the smaller grain size obtained at higher speeds, as shown in Figure 2. It has also been verified that low milling times led to heterogeneities of particle size (even at high speeds), as can be seen by the large standard deviations of the grain sizes for these times in Table 1 . In this case, the magnet exhibits very small grains $(3 \mu \mathrm{m})$ and also large grains $(\sim 45 \mu \mathrm{m})$. This effect is clearly seen in Figure $3 \mathrm{a}$ and most certainly influences the remanence since larger grains have a multi-domain structure.

Figure 4 shows the variation of the magnetic properties with milling speed for magnets produced using a constant milling time of $2.7 \mathrm{ks}$ (45 minutes). Again, the better remanence and energy product (see Table 2) were obtained for the sintered magnet milled at $200 \mathrm{rpm}$. The best $\mu_{0 \mathrm{i}} \mathrm{H}_{\mathrm{c}}$ was obtained for the magnet prepared from the alloy milled at $250 \mathrm{rpm}$, although the intrinsic coercivity for the alloy milled at $300 \mathrm{rpm}$ is quite similar. Figures 2 and $3 \mathrm{~b}$ show a reduction of the

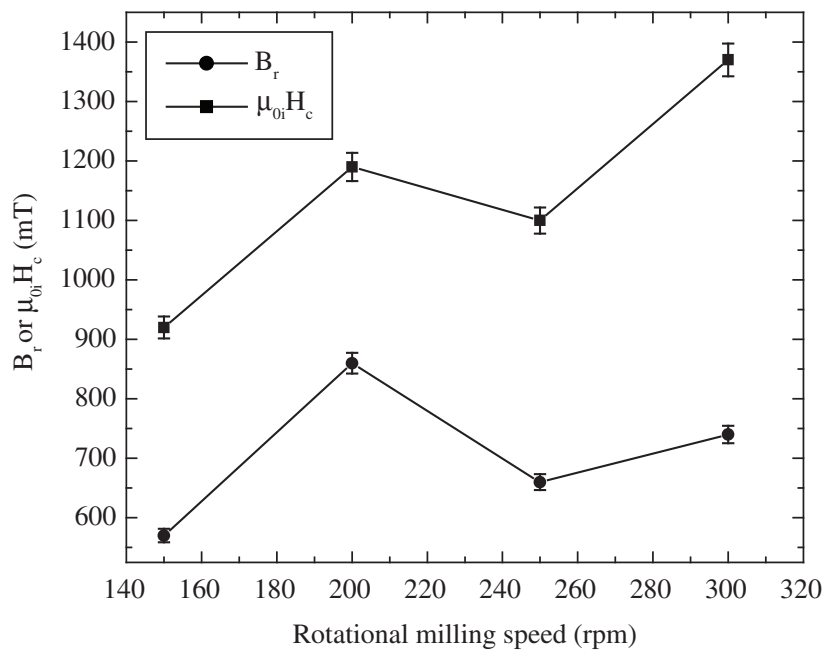

Figure 1. Variation of remanence and intrinsic coercivity with milling speed for $1.8 \mathrm{ks}$ milling time.

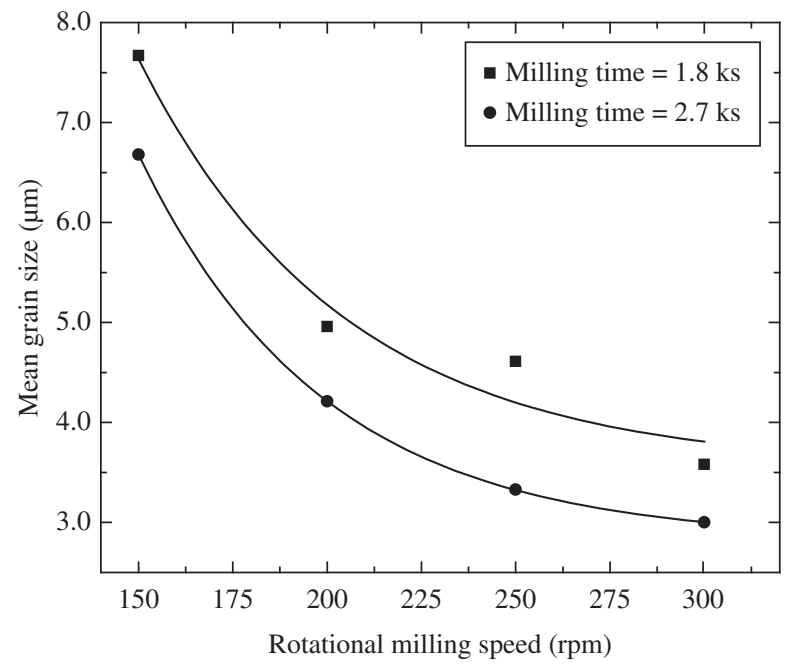

Figure 2. Variation of mean grain size with milling speed for $2.7 \mathrm{ks}$ milling time. mean gain size (about 15\%) compared to the previous case, but the heterogeneity of the microstructure (Figure $3 b$ ) is very evident, as in the previous case (Figure 3a).

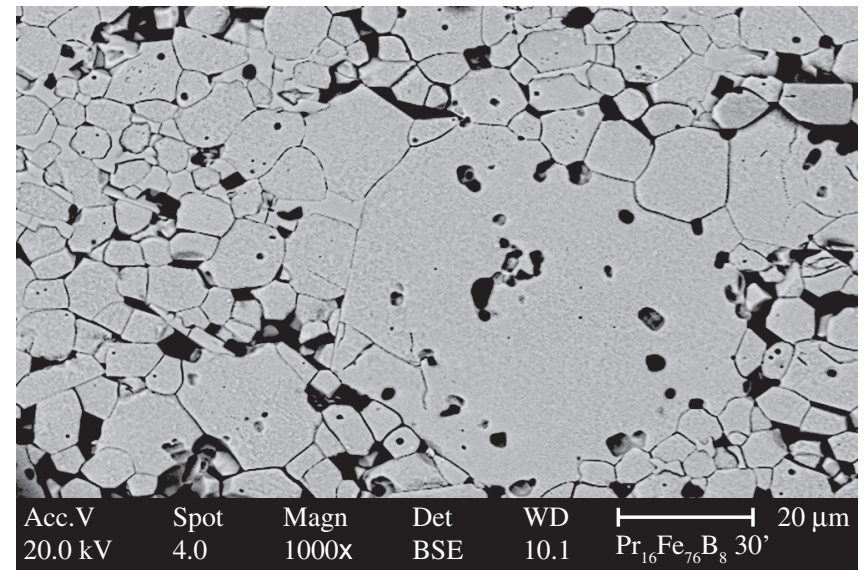

(a)

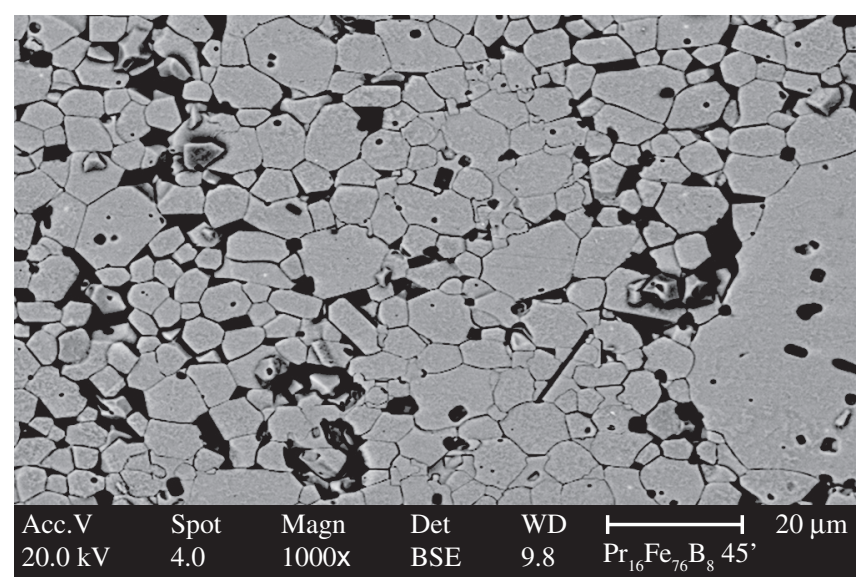

(b)

Figure 3. General view of the microstructure of $\operatorname{Pr}_{16} \mathrm{Fe}_{76} \mathrm{~B}_{8}$ magnet produced from the decrepitated ingot milled at $200 \mathrm{rpm}$ for a) 1.8 ; and b) $2.7 \mathrm{ks}$.

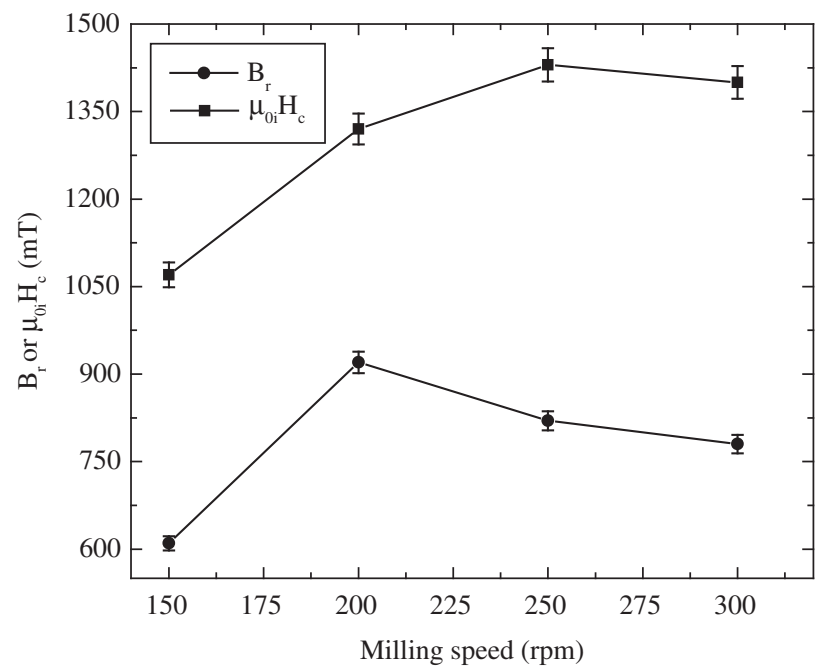

Figure 4. Variation of remanence and intrinsic coercivity with milling speed for $2.7 \mathrm{ks}$ milling time. 
Table 1. Microstructural parameters and densities for the $\operatorname{Pr}_{16} \mathrm{Fe}_{76} \mathrm{~B}_{8} \mathrm{HD}$ sintered magnets.

\begin{tabular}{|c|c|c|c|c|}
\hline Speed (rpm) & Milling time (kiloseconds) & Grain size $(\mu \mathrm{m})$ & Standard deviation $(\mu \mathrm{m})$ & Density $\left(\mathrm{gcm}^{-3}\right)( \pm 0.5 \%)$ \\
\hline \multirow[t]{2}{*}{150} & 1.8 & 7.67 & 4.59 & 7.10 \\
\hline & 2.7 & 6.68 & 2.84 & 7.10 \\
\hline \multirow[t]{5}{*}{200} & 1.8 & 4.96 & 2.78 & 7.34 \\
\hline & 2.7 & 4.21 & 2.80 & 7.35 \\
\hline & 3.6 & 3.51 & 2.00 & 7.42 \\
\hline & 4.5 & 3.08 & 1.60 & 7.48 \\
\hline & 5.4 & 2.95 & 1.68 & 7.43 \\
\hline \multirow[t]{2}{*}{250} & 1.8 & 4.61 & 2.50 & 7.37 \\
\hline & 2.7 & 3.33 & 1.59 & 7.47 \\
\hline \multirow[t]{2}{*}{300} & 1.8 & 3.58 & 1.80 & 7.46 \\
\hline & 2.7 & 3.00 & 2.05 & 7.47 \\
\hline
\end{tabular}

Table 2. Remanence, coercive field, maximum energy product and squareness factor of the $\operatorname{Pr}_{16} \mathrm{Fe}_{76} \mathrm{~B}_{8} \mathrm{HD}$ sintered magnets.

\begin{tabular}{|c|c|c|c|c|c|}
\hline Speed (rpm) & Milling time (kiloseconds) & $\mathrm{B}_{\mathrm{r}}(\mathrm{mT})( \pm 2 \%)$ & $\mu_{0 \mathrm{i}} \mathrm{H}_{\mathrm{c}}(\mathrm{mT})( \pm 2 \%)$ & $(\mathrm{BH})_{\max }\left(\mathrm{kJm}^{-3}\right)( \pm 2 \%)$ & SF (no unit) \\
\hline \multirow[t]{2}{*}{150} & 1.8 & 570 & 920 & 55 & 0.35 \\
\hline & 2.7 & 610 & 1070 & 56 & 0.20 \\
\hline \multirow[t]{5}{*}{200} & 1.8 & 860 & 1190 & 134 & 0.54 \\
\hline & 2.7 & 920 & 1320 & 162 & 0.65 \\
\hline & 3.6 & 960 & 1310 & 176 & 0.79 \\
\hline & 4.5 & 1020 & 1420 & 200 & 0.79 \\
\hline & 5.4 & 800 & 1410 & 118 & 0.70 \\
\hline \multirow[t]{2}{*}{250} & 1.8 & 660 & 1100 & 77 & 0.36 \\
\hline & 2.7 & 820 & 1430 & 121 & 0.49 \\
\hline \multirow[t]{2}{*}{300} & 1.8 & 740 & 1370 & 96 & 0.51 \\
\hline & 2.7 & 780 & 1400 & 109 & 0.46 \\
\hline
\end{tabular}

The magnetic properties for the $\operatorname{Pr}_{16} \mathrm{Fe}_{76} \mathrm{~B}_{8}$ magnet prepared from the decrepitated alloy milled for $3.6 \mathrm{ks}$ ( 60 minutes) are presented in Figure 5. There was a steady improvement in remanence up to $4.5 \mathrm{ks}$. The intrinsic coercivity showed a gradual improvement followed by a slight decrease. It was verified that the mean grain size was also reduced with longer milling time, and that the homogeneity was improved. This is clearly seen in the microstructure shown in Figure 6a. Furthermore, it was verified that the reduction grain size profile has a particular feature (an exponential decay), as presented in Figure 7.

The best magnetic properties and microstructural homogeneity were obtained for the alloy decrepitated and subsequently milled for $4.5 \mathrm{ks}$ (75 minutes). The remanence reached $1020 \mathrm{mT}$. This value is somewhat below to that $(1200 \mathrm{mT})$ reported for a $\operatorname{Pr}_{16} \mathrm{Fe}_{76} \mathrm{~B}_{8}$ magnet prepared using the "roller" ball mill ${ }^{8}$. On the other hand, $\mu_{0 \mathrm{i}} \mathrm{H}$ reached $1420 \mathrm{mT}, 10 \%$ superior than the value reported for magnets produced using $\mathrm{RBM}^{8}$. The microstructure of this sintered magnet is presented in Figure $6 \mathrm{~b}$.

The last condition studied concerns magnets obtained from the decrepitated alloy milled for $5.4 \mathrm{ks}$ ( 90 minutes). As can be seen in Figure 5, there was a reduction in $\mathrm{B}_{\mathrm{r}}$ after $4.5 \mathrm{ks}$, probably due to the reduction of the alignment degree of the $\mathrm{Pr}_{2} \mathrm{Fe}_{14} \mathrm{~B}$ phase, which will be checked using $\mathrm{X}$ ray pole figure analyses. The microstructure of the magnet processed with the powder milled for $5.4 \mathrm{ks}$ is shown in Figure $6 \mathrm{c}$. There is a similarity of the grain structure of this sample compared to the previous case ( $4.5 \mathrm{ks}$ milling), so that no significant change in the intrinsic coercivity would be expected, as verified in Figure 5.

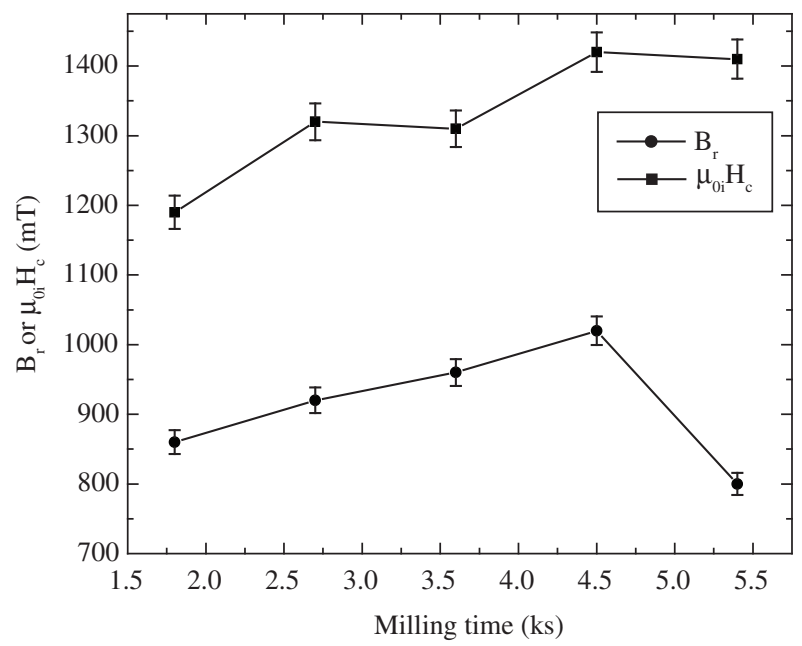

Figure 5. Variation of remanence and intrinsic coercivity with milling time for $200 \mathrm{rpm}$ milling speed.

It is worthwhile noting that increasing the milling speed, with constant milling time, results in the increase of the density of the magnets, as can be seen in Table 1, probably due to a better sinterability. A summary of the $\mathrm{HD}$ sintered $\operatorname{Pr}_{16} \mathrm{Fe}_{76} \mathrm{~B}_{8}$ microstructural parameters and densities are presented in Table 1 , and of the magnetic properties are presented in Table 2 . 


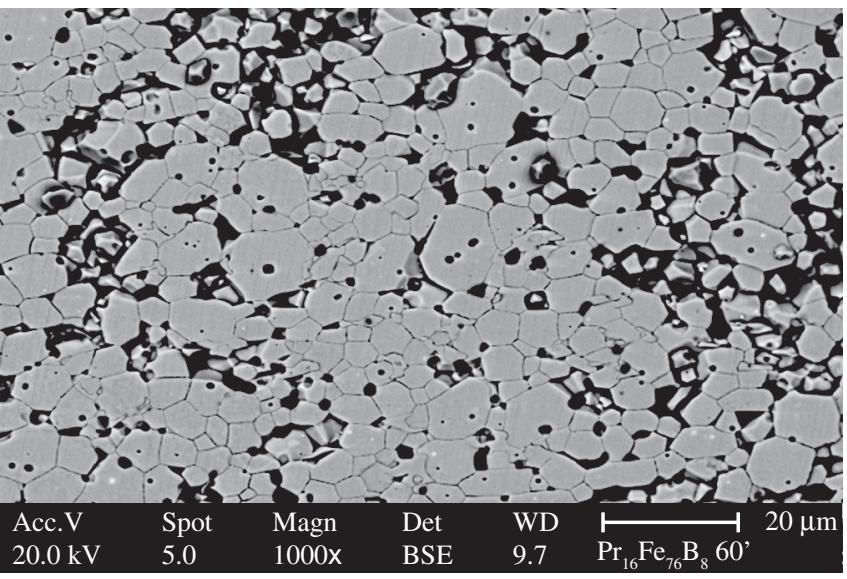

(a)

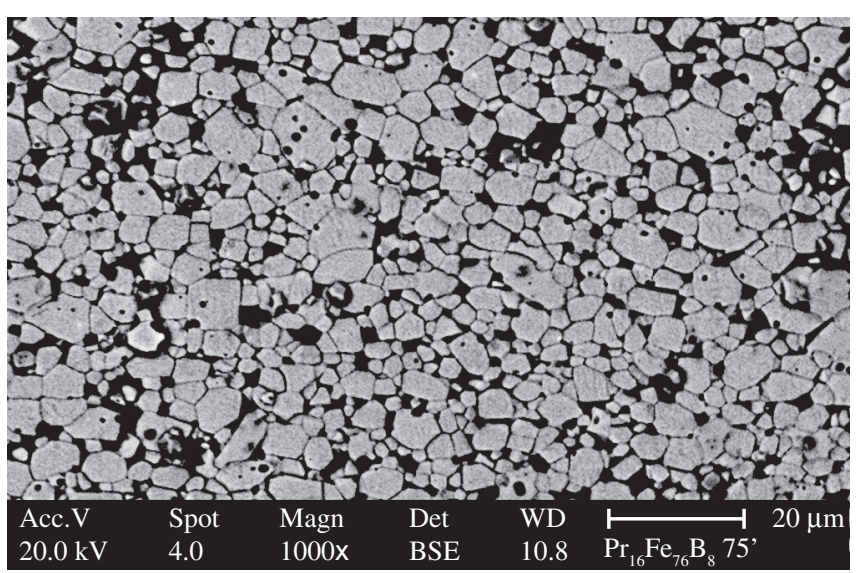

(b)

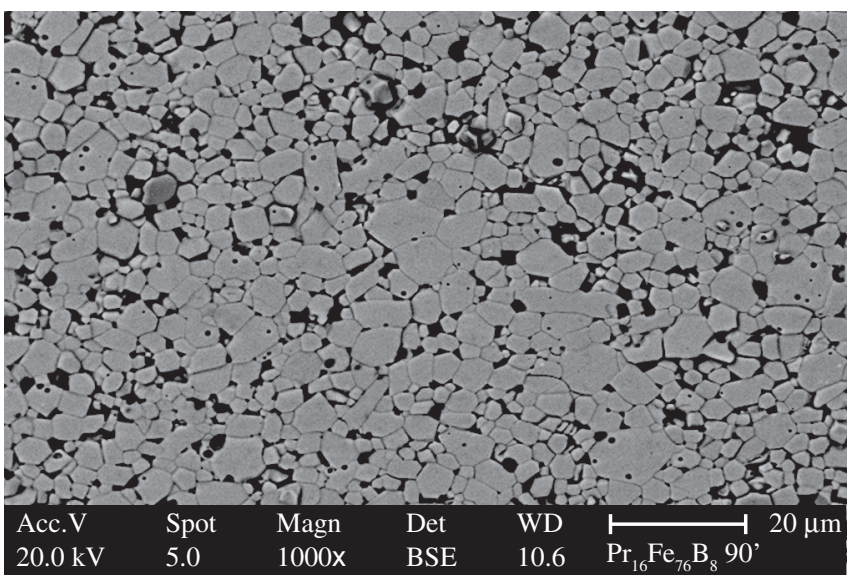

(c)

Figure 6. General view of the microstructure of $\operatorname{Pr}_{16} \mathrm{Fe}_{76} \mathrm{~B}_{8}$ magnet produced from the decrepitated ingot milled at $200 \mathrm{rpm}$ for a) 3.6 ; b) 4.5 ; and c) $5.4 \mathrm{ks}$.

\section{Conclusions}

The present studies show clearly that, employing the appropriate parameters for high-energy milling, it is possible to produce good permanent sintered magnets. Satisfactory overall magnetic properties were obtained for the magnet prepared with the alloy hydrogen decrepitated and milled at $200 \mathrm{rpm}$ for $4.5 \mathrm{ks}$ (75 minutes). High-

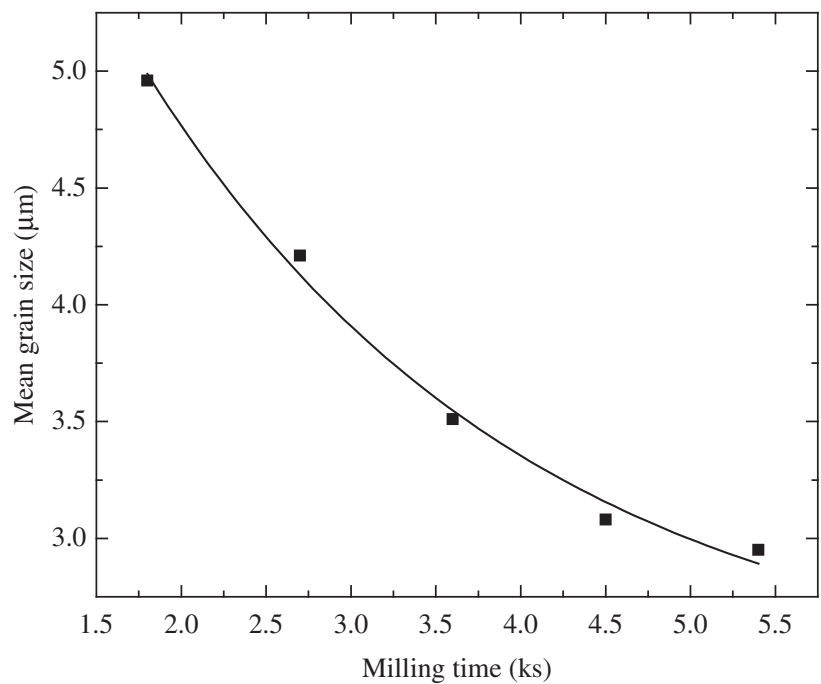

Figure 7. Exponential profile of the grain size reduction for the $\operatorname{Pr}_{16} \mathrm{Fe}_{76} \mathrm{~B}_{8}$ magnets produced from the decrepitated ingot milled at $200 \mathrm{rpm}$.

energy milling had the effect of improving the intrinsic coercivity of the PrFeB HD sintered magnet, but at the expenses of the remanence and energy product. The processing time of the magnets was dramatic reduced (around 90\%) compared with the conventional "roller" ball milling.

\section{Acknowledgments}

The authors thank IPEN-CNEN and FAPESP (Fundação de Amparo à Pesquisa do Estado de São Paulo) for supporting this investigation. E. A. Périgo also thanks FAPESP for the provision of a scholarship (contract number 2005/04711-2).

\section{References}

1. Liu, S. Magnetic alignment in powder magnet processing. Journal of Applied Physics. 1994; 76(10):6757.

2. Takiishi H, Lima LFCP, Costa I, Faria RN. The influence of process parameters and alloy structure on the magnetic properties of $\mathrm{NdDyFeBNb}$ HD sintered magnets. Journal of Materials Processing Technology. 2004; 152(1): 1 .

3. Soares EP, Périgo EA, Takiishi H, Motta CC, Faria RN. A study of PrFe-B magnets produced by a low-cost powder method and the hydrogen decrepitation process. Materials Research. 2005; 8(2):143-145.

4. Kianvash A, Harris IR. The production of a $\mathrm{Nd}_{16} \mathrm{Fe}_{76} \mathrm{~B}_{8}$ sintered magnet by the hydrogen decrepitation/ hydrogen vibration milling route. Journal of Alloys and Compounds. 1999; 282(1-2):213.

5. Mottram RS, Williams AJ, Harris IR. The effects of blending additions of copper and cobalt to $\mathrm{Nd}_{16} \mathrm{Fe}_{76} \mathrm{~B}_{8}$ milled powder to produce sintered magnets. Journal of Magnetism and Magnetic Materials. 2001; 234(1):80.

6. Christodoulou CN, Schlup J, Hadjipanayis GC. Oxidation of Fe-R-B powders during preparation of permanent magnets. Journal of Applied Physics. 1987; 61(8):3760.

7. Mcguiness PJ, Harris IR, Rozendaal E, Ormerod J, Ward, M. The production of a Nd-Fe-B permanent magnet by a hydrogen decrepitation/attritor milling route. Journal of Materials Science, 1986; 21(11):4107.

8. Faria RN. The influence of zirconium addition and process parameters on the magnetic properties of Pr-Fe-B sintered magnets. Journal of Magnetism and Magnetic Materials. 2002; 238(1):56. 